\title{
Hymenolepis diminuta
}

National Cancer Institute

\section{Source}

National Cancer Institute. Hymenolepis diminuta. NCI Thesaurus. Code C124354.

A species of tapeworm in the family Hymenolepididae with a long cylindrical body, 4 suckers, and an apical organ at its scolex with no rostellar hooks. The lifecycle of $\mathrm{H}$. diminuta involves beetles as the intermediate host and rodents as the definitive host. This tapeworm is prevalent in tropical zones worldwide but only rarely infects humans. 